\title{
IN MEMORY OF FRANCO MODIGLIANI, 1918-2003
}

\author{
Robert J. Shiller \\ Yale University
}

Franco Modigliani was a great clarifier of fundamental economic concepts. Often the mathematical rigor of our economic models is misleading, since underlying our actual use of these precisely defined models are some less-rigorous, sometimes even fallacious, concepts. Modigliani's energetic mind drove him to reflect on how our models actually function to yield policy prescriptions, and from that thinking to refine and redefine the concepts that underlie the models.

His first success was his 1944 Econometrica article "Liquidity Preference and the Theory of Interest and Money." Written in the first decade of the Keynesian revolution, it helped clarify the mishmash of ideas that Keynes had thrown out for the economics profession to deal with, and that had left many in the profession perplexed. In this first Keynesian decade, J. R. Hicks had proposed a simplified mathematical formulation of Keynes' theory that still left many questions unanswered; Oscar Lange had argued that Keynesian theory may have a fundamental contradiction surrounding Say's Law; and Abba Lerner had proposed an oversimplification of Keynes' theory that he called "functional finance," which to some economists produced intuitive, but sometimes misleading, policy prescriptions. Modigliani's paper helped lead the economics profession out of a morass of confusion and on the way to some better thinking about macroeconomic theories.

His 1954 article with Richard Brumberg as well as articles with Albert Ando over the succeeding decade brought into focus the importance of demographics in explaining saving behavior. At that time, macroeconomics was too tied up with aggregates, ignoring its microfoundations. The theory was excessively abstract in that it concerned only the representative individual while a fundamental fact of the macro economy is that it is composed of different people in different stages of their life cycles. Modigliani saw the importance of this simple fact and showed the various ramifications for macroeconomic theory. The example of Modigliani's creative work on saving behavior has set the profession on a trajectory towards better attention to the microeconomic foundations of macroeconomics.

His articles with Merton Miller, 1958-1961, about dividends, earnings, and the cost of capital have become a cornerstone of financial theory. The ModiglianiMiller theory freed us from financial thinking that is tied to artificial categories of thought and led us to thinking of the firm as a whole as an entity that merely divides up its cash flow among different classes of claimants. The theory freed us from a number of fundamental confusions that had infected our thinking until then, and changed the basic units of description for empirical finance. 
His article with Richard Sutch in 1966 has been an important model for theoretical work on the term structure of interest rates; in its modeling of expectations it was one of the events that led later to the rational expectations revolution in macroeconomics. His work in the 1970's and 1980's about the redefinition of mortgage institutions to take better account of inflation were important applications of his financial theory to economic policy. That work might have been widely applied had not the decline of inflation around the world after 1981 deflected interest from these ideas. His article about the relation of inflation to the stock market with Richard Cohn in the Financial Analysts Journal in 1979 made a fundamental contribution to our understanding of fluctuations in market valuations, a precursor to the behavioral finance revolution.

His research with Albert Ando and the staff of the Board of Governors on the FRB-MIT-Penn (Federal Reserve Board-Massachusetts Institute of TechnologyUniversity of Pennsylvania) Model of the U. S. economy yielded what was probably the world's most influential example of large-scale macroeconometric modeling. Although the model was never brought to perfection before it was finally abandoned, Modigliani's method of understanding the relation between theory and data continues to influence macroeconomic models to this day.

Modigliani had a clear focus in his work, towards finding economic policies for improving human welfare. "Economists should be ready to participate in policy," he said in his Macroeconomic Dynamics interview in this journal in June 2000, and his professional life has shown his commitment to this end. This focus led him to apply his work towards influencing policy judgments in the United States, in his native Italy, in the European Union, and throughout the world.

I personally remember him from my graduate student days during the Vietnam War, not only as a wonderful role model for a style of economic research, but also as someone unusually involved in moral and humanitarian issues. He is someone who has been a powerful constructive force in bringing the field of economics to the service of the world around us. 